\title{
Reinfecções e desenvolvimento da fibrose periportal esquistossomótica no modelo murino
}

\author{
Reinfections and the development of schistosomal \\ periportal fibrosis in the murine model
}

Antonio Benigno Araújo Santos, Marcia Maria de Souza e Zilton A. Andrade

\begin{abstract}
Resumo A fibrose periportal esquistossomótica observada no modelo murino apareceu muito mais freqüentemente $(69,2 \%)$ em camundongos submetidos à múltiplas infecções pelo Schistosoma mansoni do que naqueles animais com infecção única $(11,1 \%)$. A contagem dos ovos depositados no fígado não diferiu significativamente nos dois grupos ao término dos experimentos. Embora não tenha ficado esclarecido o motivo pelo qual as infecções repetidas favorecem o desenvolvimento da fibrose periportal esquistossomótica, os dados observados fornecem apoio experimental às observações clínico-epidemiológicas que sugerem ter as reinfecções um papel na patogenia da forma hepato-esplênica da esquistossomose.
\end{abstract}

Palavras-chaves: Fibrose periportal. Esquistossomose. Reinfecções.

Abstract Experimental pipestem fibrosis of the liver developed more frequently (69.2\%) in mice submitted to repeated infections with Schistosoma mansoni, than with single infection (11.1\%). The counting of eggs in the liver revealed no significant differences between the two experimental groups. Although the reason why multiple infections favor the development of pipestem fibrosis has not been elucidated, the data obtained represent an experimental support to clinicoepidemiological claims that repeated infections play a role in pathogenesis of hepatosplenic schistosomiasis.

Key-words: Periportal fibrosis. Schistosomiasis. Reinfections.

Os pesquisadores com experiência em trabalhos de campo têm suspeitado que as reinfecções pelo Schistosoma mansoni representam um fator adicional de importância no desenvolvimento da forma hepato-esplênica da doença. A base desta suspeita deriva da observação de que os indivíduos infectados que migram para fora da área endêmica não mais desenvolvem a forma hepato-esplênica ${ }^{511} 12$. Os que já estão com esta forma da doença têm melhor prognóstico quando fora da área endêmica e, quando tratados ou quando a transmissão é interrompida, têm mais chances de regressão do que os que permanecem em áreas de transmissão ativa ${ }^{4}$.

Alguns dados da patologia experimental aparentemente apoiam esta tese, pois o desenvolvimento da chamada fibrose pipestem no chimpanzé só foi obtida com infecções múltiplas ${ }^{16}$. Há também um dado experimental indicativo de que os granulomas nos camundongos reinfectados são maiores do que naqueles com infecção única ${ }^{9}$.

Um modelo mais adequado para se reproduzir a fibrose pipestem em camundongos foi descrito por Warren ${ }^{22} \mathrm{em} 1966$. Este modelo foi mais recentemente melhor avaliado e caracterizado ${ }^{12}$.

O presente estudo lança mão deste modelo para avaliar se as reinfecções pelo $S$. mansoni, resultam numa maior proporção de casos de fibrose pipestem do fígado, em comparação com controles submetidos à uma única infecção.

Laboratório de Patologia Experimental do Centro de Pesquisa Gonçalo Moniz/FIOCRUZ, Salvador, BA, Brasil.

ABA Santos é bolsista de Iniciação Científica do CNPq.

Endereço para correspondência: Prof. Zilton A. Andrade. Centro de Pesquisa Gonçalo Moniz/FIOCRUZ. Rua Valdemar Falcão 121, 40295-001 Salvador, BA, Brasil

Tel: 5571 356-8787, Ext. 206; fax: 5571 356-4292.

Recebido para publicação em 15/3/99. 


\section{MATERIAL E MÉTODOS}

Camundongos albinos suíços, 15-18 gramas, de ambos os sexos, mantidos com dieta comercial balanceada e água ad libitum, foram submetidos à infecção por via transcutânea, com 30 cercárias recentemente eliminadas por diversos caramujos (Biomphalaria glabrata) criados e infectados em laboratório.

Sessenta dias após a exposição cercariana, com os animais eliminando ovos viáveis do $S$. mansoni nas fezes, os mesmos foram divididos ao acaso em dois grupos sendo que a metade foi simplesmente separada e mantida em observação. A outra metade foi submetida a nova exposição, com cerca de 10/15 cercárias, a cada 15 dias, perfazendo um total de 5 reinfecções. Trinta dias após a última reinfecção os animais foram sacrificados, isto é 20 semanas após o início das infecções cercarianas. Ao todo, 26 animais do grupo reinfectado e 18 controles foram examinados com a mesma metodologia descrita a seguir: sob anestesia pelo éter, o abdômen foi aberto na linha mediana e a aorta seccionada. Fragmentos do fígado foram fixados em líquido de Bouin por seis horas para exame histológico. Após inclusão em parafina, as secções coradas pela hematoxilina-eosina e o pelo método do sírius vermelho para colágeno ${ }^{15}$ foram examinadas independentemente pelos três autores, que não tinham outra informação senão um número de código escrito em cada lâmina. As poucas discordâncias que surgiram na classificação dos casos foram discutidas e resolvidas antes que as lâminas fossem decodificadas.

Para a contagem dos ovos no fígado uma parte deste órgão foi digerido em potassa segundo o método de Cheever ${ }^{7}$.

\section{RESULTADOS}

Com a lente de campo do microscópio, as secções coradas pelo método do sírius-vermelho foram facilmente separadas, em sua maioria, em dois grupos: um que mostrava uma concentração de granulomas periovulares nas áreas periportais (Figura 1) e outro onde os granulomas apareciam como que isolados uns dos outros (Figura 2). No primeiro caso os granulomas formavam faixas mais ou menos densas de fibrose, que

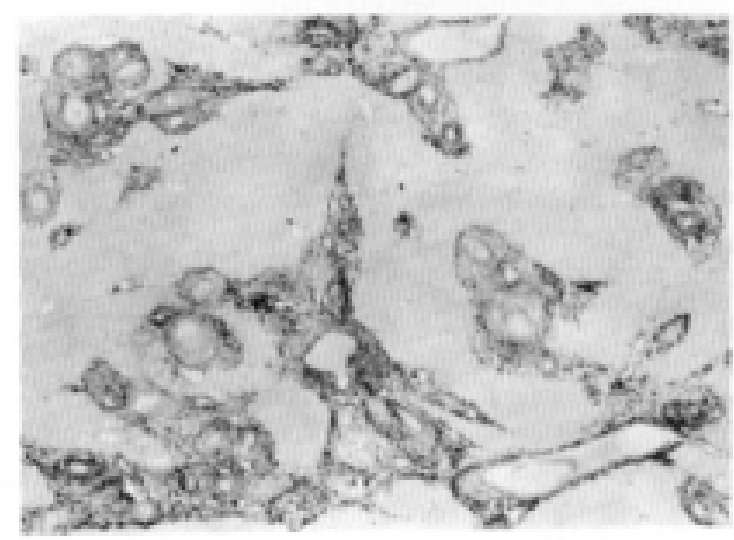

Figura 1 - Exemplo de lesão pipestem. Os granulomas confluem nos espaços porta, associam-se com um certo grau de fibrose extragranulomatosa e formam faixas que conectam espaços porta entre si, deixando amplas áreas do parênquima livres de granulomas e com a estrutura trabecular normal do fígado. Método do sírius-vermelho para colágeno, $100 x$. freqüentemente conectavam entre si vários espaços porta, deixando largas faixas do parênquima sem alterações evidentes, a não ser pela presença de pigmento enegrecido no interior de células sinusoidais. Em uns poucos casos, as duas alterações apareciam numa mesma secção. As alterações observadas aparecem na Tabela 1. A Tabela 2 mostra o resultado das contagens de ovos no fígado dos animais.

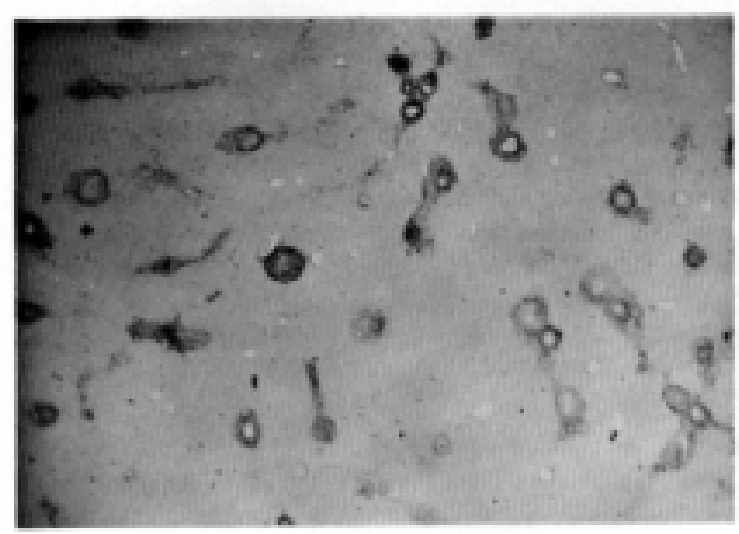

Figura 2 - Exemplo da lesão representada por granulomas isolados. Os granulomas periovulares, isolados ou aos pares, aparecem dissociados entre si e distribuem-se ampla e esparsamente pelo tecido hepático. Método do sírius-vermelho para colágeno, $64 x$. 
Tabela 1 - Desenvolvimento de fibrose pipestem em fígados de camundongos com infecção única e com múltiplas infecções pelo Schistosoma mansoni.

\begin{tabular}{lcccc}
\hline Grupos & $N^{\circ}$ animais & c/Pipestem & c/Granulomas isolados & Mixtos \\
\hline Reinfectados & 26 & $18(69,2 \%)$ & $6(23,0 \%)$ & $2(7,6 \%)$ \\
Controles & 18 & $2(11,1 \%)$ & $13(72,2 \%)$ & $3(16,6 \%)$ \\
\hline
\end{tabular}

Tabela 2 - Média dos ovos do Schistosoma mansoni por grama de tecido hepático em camundongos com infecção única e com múltiplas infecções

\begin{tabular}{llcc}
\hline Grupos & no & Média & Desvio padrão \\
\hline Infecção simples & 18 & $10.925,17$ & $5.124,63$ \\
Infecções repetidas & 26 & $12.139,03$ & $5.343,64$
\end{tabular}

Teste não paramétrico de Mann-Witney .

$p>0,05$. Valor de $p=0,6819$

\section{DISCUSSÃO}

Os resultados observados indicaram claramente que os animais reinfectados pelo $S$. mansoni exibiram uma maior proporção de fibrose periportal em comparação com os animais com infecção única. Estes dados são válidos para o modelo murino. Não podem ser transpostos acriticamente para a patologia humana. Uma avaliação do modelo, considerado como representativo da fibrose pipestem descrita por Symmers ${ }^{21}$ no homem, já foi apresentado ${ }^{2}$. Há nos dois casos semelhanças e diferenças, mas, no conjunto, o modelo murino aparece como o mais adequado, simples e barato, para estudos sobre a patogenia da forma grave da esquistossomose, como estudos recentes têm demonstrado ${ }^{31314}$. A primeira e mais simples explicação para os resultados aqui obtidos basear-se-ia numa diferença de carga parasitária entre os dois grupos experimentais. Infecções múltiplas resultariam em acumulação de carga parasitária, um fator que já foi evidenciado como primordial para o desenvolvimento da forma hepato-esplênica ${ }^{6}{ }^{18}$. Todavia, a contagem de ovos no fígado não revelou diferenças estatisticamente significantes entre os dois grupos. Os camundongos com infecção crônica pelo $S$. mansoni desenvolvem uma circulação colateral no sistema porto-cava, que pode desviar os vermes imaturos de uma segunda infecção para sítios extra-hepáticos periféricos, um habitat inadequado que causaria a morte de muitos vermes $^{1723}$. Talvez a destruição destes novos vermes e a morte de esquistossômulos, periodicamente, venham a estimular ou modificar o comportamento vascular intra-hepático ou outros fatores envolvidos na reatividade aos vermes e seus produtos. Fatores imunológicos podem ser particularmente estimulados, mas estes últimos não estão ainda bem definidos ${ }^{810}$. Fatores reacionais diversos apareceram em outro trabalho como a explicação mais plausível para a incapacidade de camundongos desnutridos desenvolverem o modelo da fibrose pipestem ${ }^{13}$.

\section{REFERÊNCIAS}

1. Andrade ZA. Pathogenesis of pipestem fibrosis of the liver (Experimental observations on murine schistosomiasis). Memorias do Instituto Oswaldo Cruz 82:325-334, 1987.

2. Andrade ZA, Cheever AW. Characterization of the murine model of schistosomal hepatic periportal fibrosis ("Pipestem" fibrosis). International Journal of Experimental Pathology 74:195-202, 1993.

3. Andrade ZA, Silva LM, Souza MM, Sadigursky M, Barbosa Jr AA, Oliveira IR. Role of the spleen on the pathogenesis of schistosomal periportal (pipestem) fibrosis of the liver: an experimental approach. American
Journal of Tropical Medicine and Hygiene 59:557-562, 1998.

4. Bina JC. Estudo de variáveis que podem influenciar na evolução da esquistossomose mansônica: efeito da terapêutica específica e da interrupção do tratamento. Tese de Doutorado, UFBA, Salvador, BA, 1995.

5. Bina JC, Prata A. Evolução natural da esquistosomose em uma área endêmica. Aspectos Peculiares da infecção por Schistosoma mansoni. Publicações do Centro de Estudos de Doenças Regionais Endêmicas (CEDRE), Salvador, BA, p.13-34, 1984. 
6. Cheever AW. A quantitative post-mortem study of schistosomiasis mansoni in man. American Journal of Tropical Medicine and Hygiene 17: 38-64, 1968.

7. Cheever AW. Relative resistance of the eggs of human schistosomes to digestion in potassium hydroxide. Bulletin of the World Health Organization 43: 601-603, 1970.

8. Cheever AW. Schistosomiasis: infection versus disease and hypersensitivity versus immunity. American Journal of Pathology 142:699-702, 1993.

9. Coelho PM, Toppa NH, Mello RT, Feldmann JS, Gonçalves R. Schistosoma mansoni: exacerbation of inflammatory granulomatous response in mice chronically infected and submitted to reinfection. Revista do Instituto de Medicina Tropical de São Paulo 38:303-305, 1996.

10. Colley DG, Garcia AA, Lambertucci JR, Parra JC, Katz N, Rocha RS, Gazzinelli G. Immune responses during human schistosomiasis. XII. Differential responsiveness in patients with hepatosplenic disease. American Journal of Tropical Medicine and Hygiene 35:793-802, 1986.

11. Coura JR. Follow up of patients with schistosomiasis living in non-endemic area in Brazil. Brasília-Médica 2:45-47, 1975.

12. Coura JR, Wanke B, Fiqueiredo N, Argento CA. Evolutive pattern of schistosomiasis and life-span of Schistosoma mansoni in patients living in non-endemic area in Brazil. Revista da Sociedade Brasileira de Medicina Tropical 8:193-198, 1974.

13. Coutinho EM, Souza MM, Silva LM, Cavalcanti CL, Araújo RE, Barbosa Jr AA, Cheeve AW, Andrade ZA. Pathogenesis of Schistosomal pipestem Fibrosis (A Lowprotein diet inhibits the development of pipestem fibrosis in mice). International Journal of Experimental Pathology 78:337-342, 1997.

14. Henderson GS, Nix NA, Montesanm A, Gold D, Freeman Jr GL, McCurley TL, Colley DG. Two distinct pathological syndromes in male CBA/J inbred mice with chronic Schistosoma mansoni infections. American Journal of Pathology 142:703-714, 1993.
15. Junqueira LCU, Bignolas G, Brentani RR. Picrosirius staining plus polarization microscopy, a specific method for collagen detection in tissue sections. Histochemical Journal 11:447-455, 1979.

16. Lichtenberg F, Sadun E. Experimental production of bilharzial pipestem fibrosis in the chimpanzee. Experimental Parasitology 22:264-278, 1968.

17. Medeiros MV, Andrade ZA. The importance of collateral portal veins for resistance to schistosomiasis in mice. Brazilian Journal of Medical and Biological Research 19:85-88, 1986.

18. Prata A. Fatores determinantes das formas anátomoclínicas e evolução da esquistossomose. In: Castro FP et al (eds) Tópicos em Gastroenterologia. Rio de Janeiro, MEDSI - Editora Médica e Científica Ltda, p. 3-12, 1991.

19. Sadun EH, Lichtenberg F, Cheever AW, Erickson DG. Schistosomiais mansoni in the chimpanzee. The natural history of chronic infections after single and multiple exposures. American Journal of Tropical Medicine and Hygiene 19:258-277, 1970.

20. Satti MZ, Sulaiman SM, Homeida MM, Younis SA, Ghalib HW. Clinical, parasitological and immunological features of canal cleaners hyper-exposed to Schistosoma mansoni in the Sudan. Clinical and Experimental Immunology 104:426-431, 1996.

21. Symmers WSTC. Note on a new form of liver cirrhosis due to the presence of the ova of Bilharzia haematobia. Journal of Pathology and Bacteriology 9:237-239, 1904.

22. Warren KS. The pathogenesis of "clay-pipestem cirrhosis" in mice with chronic schistosomiasis mansoni, with a note on the longevity of the schistosomes. American Journal of Pathology 49:477-489, 1966.

23. Wilson RA, Coulson PS, McHugh SM. A significant part of "concomitant immunity" of mice to Schistosoma mansoni is the consequence of a leaky hepatic portal system, not immune killing. Parasite Immunology 5:595601, 1983. 